\title{
Surface Hardening of Ductile Cast Iron by Electrolytic Plasma Technology
}

\author{
A. AYDAY* AND M. DURMAN
}

Sakarya University, Faculty of Engineering, Department of Metallurgical and Materials Engineering Sakarya, 54187, Turkey

Traditional surface modification obligations, surface coatings, and other methods of surface treatment are used to increase the hardness and mechanical properties of specimen surfaces. But those techniques are limited due to the high equipment cost, and material consumption. Electrolytic plasma technology is a special heat treatment process employing electrolysis in an aqueous solution under particular conditions, for instance voltage, current, electrolyte, duration, and heating-quenching rate. In this study, surface modification of GGG70 cast iron was carried out by using electrolytic plasma treatment. Certain voltage and ampere values were performed to obtain good surface properties. Metallographic studies were carried out with an optical microscope to study the hardened and modified surfaces. The effect of impulse time on surface temperature was investigated and it was observed that the temperature on the workpiece increased with increasing impulse time. It was found that the electrolytic plasma treatment could significantly increase hardness of the cast iron.

DOI: 10.12693/APhysPolA.123.291

PACS: 81.30.Kf, 82.33.Xj, 68.35.bd

\section{Introduction}

The use of ductile iron (DI) has increased continuously since its introduction in the market in the 1950s, because of its good combination of strength and toughness, high fatigue endurance and relatively low cost. In the later nineties the development of DI introduced the use of thin walled parts, in order to increase the strength to weight ratio and its competitiveness against light alloys [1, 2].

Presently the electrolytic plasma treatment (EPT) is frequently used in the field of surface engineering. Primarily its high localized energy input at the surface and the high velocity of the diffusion are the most important advantages. In addition, EPT systems can be efficiently combined with automated machines enabling industrial applications. Among other surface treatments, EPT hardening is one of the most promising as an alternative to other surface hardening techniques, such as induction or flame hardening, laser hardening since it is associated with lower distortion of parts as well as it can be more easily adapted to automation than other methods. This method is mainly used for ferrous alloys (non alloyed-steels, tool steels and cast irons) which undergo martensite transformation and thus form a very hard surface layer with negligible surface roughness and distortion. The surface treated zones have an average depth of 0.1-10 $\mathrm{mm}$ and exhibit increased hardness, improved resistance to wear, better corrosion resistance, and higher fatigue strength (e.g. piston ring groove, valve seat, compressor screws, diesel engine cylinder liners, gears etc.). This paper reports the results of EPT of the ductile iron and examines the optimization of the method and the resulting surface properties of the treated material $[3,4]$.

\section{Experimental}

Ductile iron has a composition of $3.22 \% \mathrm{C}, 2.51 \% \mathrm{Si}$ $0.104 \%$ Mn, $0.768 \%$ Cu, 0.0444\% Cr, 0.060\% P, 0.011\% S,

\footnotetext{
*corresponding author; e-mail: aayday@sakarya.edu.tr
}

$0.0411 \% \mathrm{Mg}$ and iron. The electrolytic plasma treatment parameters are listed in Table. Microstructure studies of the treated surfaces were performed with the aid of an optical microscope. Rockwell hardness profiles of the surface were measured using a load of $150 \mathrm{kgf}$.

To study the effect of process parameters, the dimensions of $40 \times 40 \times 15 \mathrm{~mm}^{3}$ specimens were machined from the test section of the Y-block. A $3 \mathrm{~mm}$ diameter hole was drilled up to a depth of $14 \mathrm{~mm}$ at the center of the specimen to house the thermocouple for temperature measurement. A K-type digital thermometer and data-logger was used to record temperature. Voltage current data were collected from the system with the help of data acquisition system interfaced with a computer.

\section{Results and discussion}

Electrolytic plasma treatment optimization - impulse time/pause time relationship and temperature profile microstructure analysis is considered. The ductile iron surfaces were modified by using electrolytic plasma technique. To modify the surface different impulse time were chosen (Table). Metallographic analysis revealed that the heat treated zone had a depth varying between $0.5 \pm 0.1$ and $5 \pm 0.1 \mathrm{~mm}$ depending on the treatment conditions. The microstructure near the surface was more homogeneous and exhibited finer grains than the as-received material. Phase transformation occured in hardened zone (HZ). As it is known, during EPT processing austenite forms during heating dissolve in the phase. During cooling, austenite transforms completely or partially to martensite and thus the microstructure of the $\mathrm{HZ}$ consists of martensite containing (very often or probably) a small amount of retained austenite, respectively. In the neighborhood of the $\mathrm{HZ}$ with the base material, a transition zone is observed, consisting of martensite, some traces of the initial pearlitic structure. These are the most probable structures, according to Refs. [5] and [6]. 
EPT parameters.

TABLE

\begin{tabular}{c|c|c|c|c|c}
\hline \hline Parameter code & Electrolytic solution & Impulse [V] & Pause [V] & Total time [s] & Cycle \\
\hline $\mathrm{A}$ & $\mathrm{Na}_{2} \mathrm{CO}_{3} ; 12 \%$ & 310 & 250 & $(3-3) \times 6-36 \mathrm{~s}$ & 6 \\
$\mathrm{~B}$ & $\mathrm{Na}_{2} \mathrm{CO}_{3} ; 12 \%$ & 310 & 250 & $(2-3) \times 6-30 \mathrm{~s}$ & 6 \\
$\mathrm{C}$ & $\mathrm{Na}_{2} \mathrm{CO}_{3} ; 12 \%$ & 310 & 250 & $(1-3) \times 6-24 \mathrm{~s}$ & 6
\end{tabular}

Figure 1 shows the microstructure of cross-section of the EPT treated ductile iron.

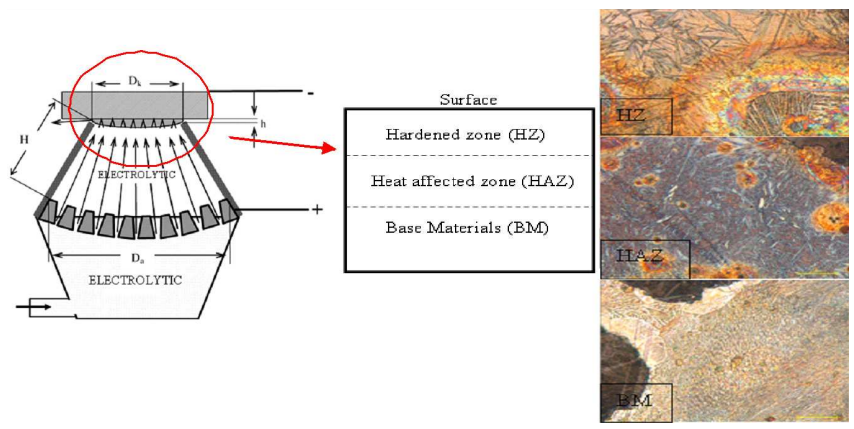

Fig. 1. Geometry of specimens for EPT-scheme showing the regions of the EPT zone and microstructure of modified DI.

Figure 2 shows the longitudinal hardness profiles of both treated specimens. The hardness of the ductile iron was 10 HRC. The surface hardness of the specimens increases considerably after electrolytic plasma treatment. The very high hardness values in the HZ (63 HRC) compared to those of the base materials (BM) (10 HRC) can be attributed to the martensite formation [5-7].

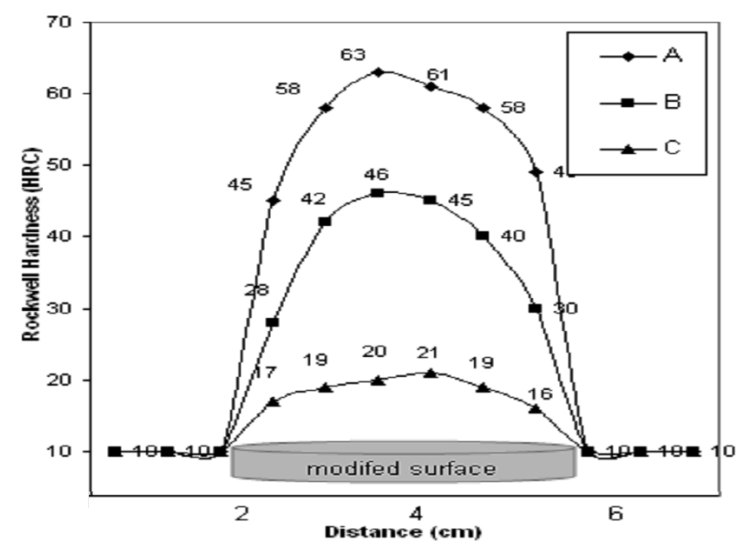

Fig. 2. Surface hardness profiles of A-B-C code samples.

All profiles show maximum hardness in the centre that corresponds to the martensitic structure. A hardness across the EPT-track decreases rapidly by about $20 \mathrm{~mm}$ from its centre, whereas the EPT is significantly wider. This fact can be explained by looking the shape and intensity profile of the EPT. The exposure (heating) time is lower in the border of the EPT-tracks due to the elliptical nozzle shape. The combination of those two effects results in significantly lower temperatures reached in the external limits of the modified zone, temperatures at which austenization does not take place, so no hard quenched martensite can be achieved.

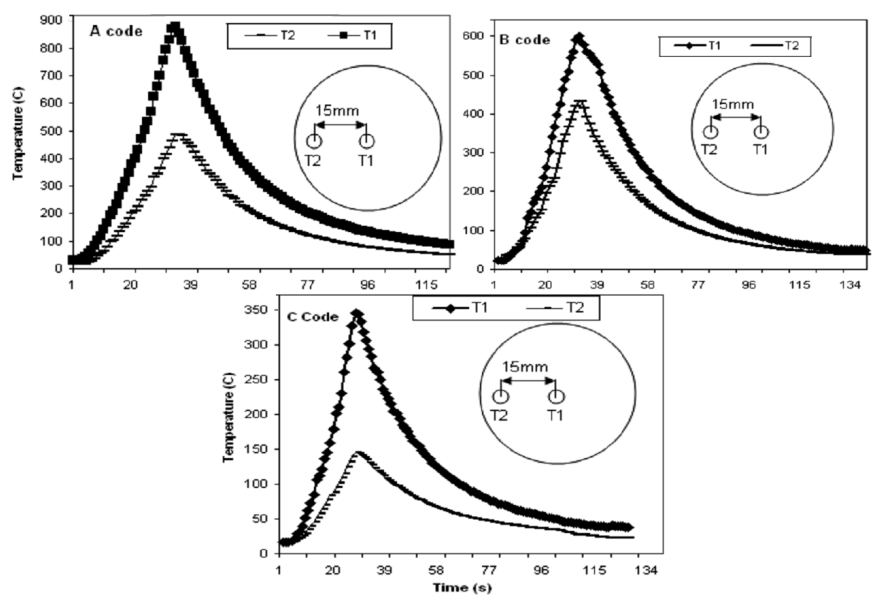

Fig. 3. The heating and cooling curves of $A-B-C$ code samples.

Figure 3 shows the variation of surface temperatures during EPT. Temperature profiles are given as a function of impulse time/total time and at different hole of surface on specimens (T1/T2). All center holes (T1) of the samples had higher temperature values than border holes (T2). It can be noticed from Fig. 3 that the maximum temperature is $900^{\circ} \mathrm{C}$, and it decreases by decreasing the impulse time. The calculated temperature results show that the temperature in the spot center of the EPT could not melt the samples surface, while the heating process which could lead new phases can be formed.

\section{Conclusion}

Surface modification of DI by EPT was carried out to achieve a fine microstructure with increased hardness. Martensitic structure formed in the $\mathrm{HZ}$ region of DI. The average hardness of the modified layer increased with increasing the impulse time. Increasing the impulse time caused high surface temperature and the heating process which could lead to hard martensite structure can be formed. The maximum surface hardness was seen on A code samples after EPT. 


\section{References}

[1] G. Francucci, J. Sikora, R. Dommarco, Mater. Sci. Eng. A 485, 46 (2008)

[2] M. Shamanian, S.M.R. Mousavi Abarghouie, S.R. Mousavi Pour, Mater. Des. 31, 2760 (2010).

[3] S.F. Luk, T.P. Leung, W.S. Miu, I. Pashby, J. Mater. Proc. Technol. 91, 245 (1999)

[4] Y.N. Tyurin, A.D. Pogrebnjak, Surf. Coat. Technol. 142-144, 293 (2001)
[5] A.F. Vicente, M. Pellizzari, J.L. Arias, J. Mater. Proc. Technol. 212, 989 (2012)

[6] J.H. Abboud, K.Y. Benyounis, A.G. Olabi, M.S. Hashmi, J. Mater. Proc. Technol. 182, 427 (2007)

[7] Y. Chen, C.H. Gan, L.X. Wang, G. Yu, A. Kaplan, Appl. Surf. Sci. 245, 316 (2005). 